\title{
Fluoride Ion Receptors Based on Dipyrrolyl Derivatives Bearing Electron Withdrawing Groups: Synthesis, Optical and Electrochemical Sensing and Computational Studies
}

\author{
Tamal Ghosh and Bhaskar G. Maiya \\ School of Chemistry, University of Hyderabad, Hyderabad 500 046, India
}

Fax: (+91) 40-2301-2460

Ming Wah Wong*

Department of Chemistry, National University of Singapore,

3 Science Drive 3, Singapore 117543

Fax: (+61)67791691 ,E-mail: chmwmw@nus.edu.sg

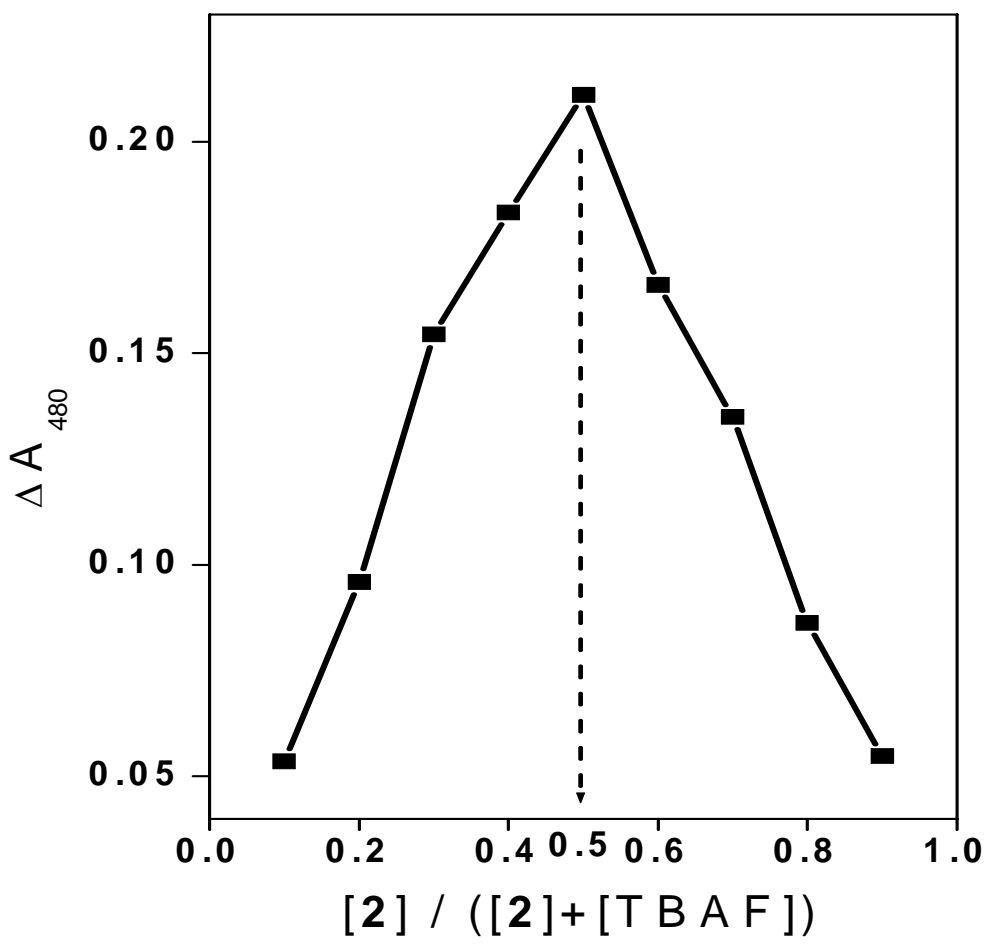

Fig. S1. The representative stoichiometric analysis of the fluoride complex $2-\mathrm{F}^{-}$by Job

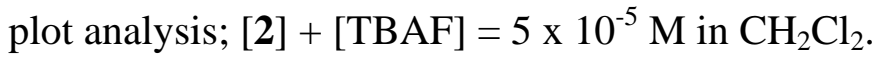



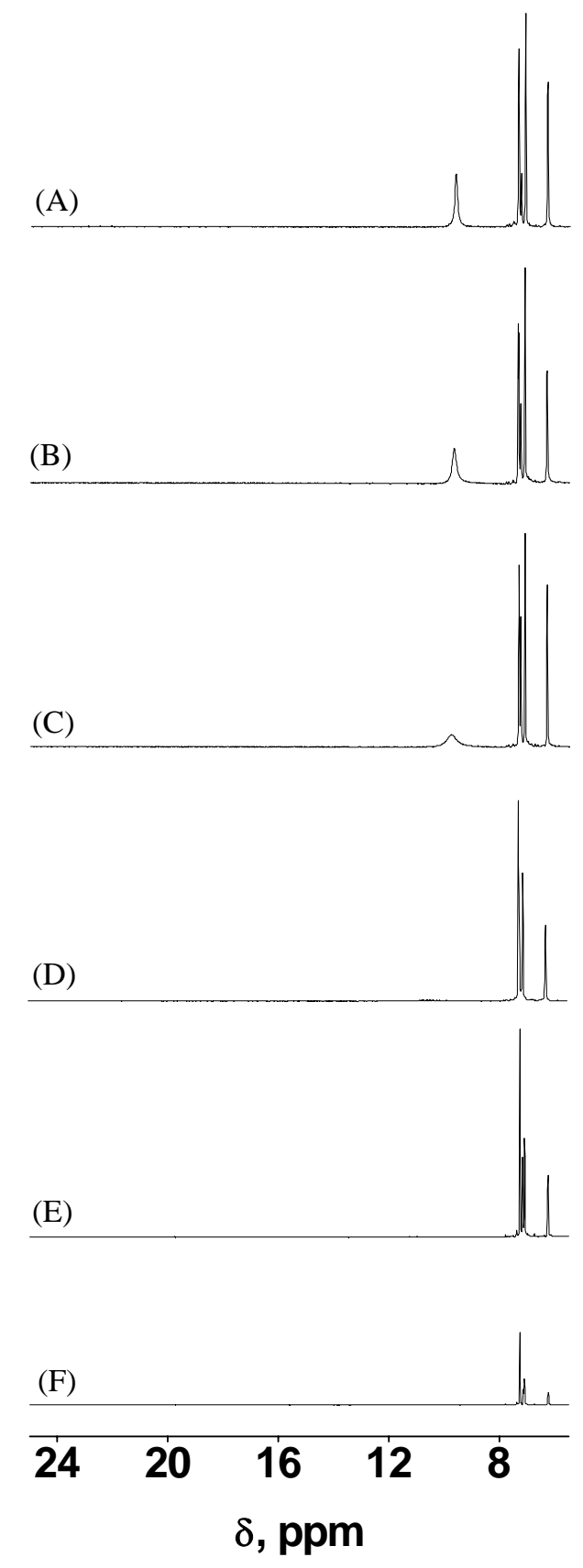

Fig. S2. ${ }^{1} \mathrm{H}$ NMR titration of 2 with TBAF in $\mathrm{CDCl}_{3}$; [2] = $3.84 \times 10^{-2} \mathrm{M}$; [2] : [F $]$ in these traces are : (A) $1: 0$, (B) $1: 0.045$, (C) $1: 0.1$, (D) $1: 0.5$, (E) $1: 1$ and (F) $1: 1.5$. 